\title{
Study on Emission Reduction Strategies of Dual-Channel Supply Chain Considering Green Finance
}

\author{
Cheng Che ${ }^{1 t}$, Yi Chen ${ }^{1 * t}$, Xiaoguang Zhang ${ }^{1}$, Liangyan Zhao ${ }^{1}$, Peng Guo ${ }^{2}$ and Jingwen Ye ${ }^{1}$ \\ ${ }^{1}$ School of Economics and Management, China University of Petroleum, Qingdao, China, ${ }^{2}$ Livestock Improvement Cooperation, \\ Hamilton, New Zealand
}

OPEN ACCESS

Edited by:

Qiang Ji,

Institutes of Science and

Development, Chinese Academy of

Sciences, China

Reviewed by:

Pali Rosha,

Indian Institute of Technology

Bombay, India

Dexiang Zhang,

Qingdao University, China

Li Gaoguang,

Beijing International Studies University,

China

*Correspondence:

Yi Chen

934358114@qq.com

${ }^{\dagger}$ These authors contributed equally to the present work

Specialty section:

This article was submitted to

Environmental Economics and

Management,

a section of the journal

Frontiers in Environmental Science

Received: 29 March 2021

Accepted: 21 May 2021

Published: 10 June 2021

Citation:

Che $C$, Chen $Y$, Zhang $X$, Zhao L,

Guo $P$ and $Y$ e J (2021) Study on Emission Reduction Strategies of DualChannel Supply Chain Considering

Green Finance.

Front. Environ. Sci. 9:687468. doi: 10.3389/fenvs.2021.687468
As a weapon for economic development, green finance plays an important supporting and promoting role in the economic recovery and transformation of enterprises in the postepidemic era. By constructing a dual-channel supply chain model, this paper considers two situations in which manufacturers participate in carbon trading and green finance loans, and uses Stackelberg game to study the impact of different situations on participants' profits and emission reduction decisions. The results show that: under the carbon trading mechanism, the carbon emission reduction level of the manufacturer is inversely proportional to the relevant price, and the demand and profit of the two channels increase with the increase in emission reduction; when carbon trading and green financial loans are carried out at the same time, participants have lower profits, but with the increase in emission reductions, it is still a growing trend.

Keywords: green finance, carbon trading, carbon emission reduction, dual-channel, stackelberg game

\section{INTRODUCTION}

The outbreak of COVID-19 in early 2020 caused a global economic downturn, and its impact on the economy even exceeded the 2008 financial crisis (Li, 2020). Due to the needs of management and control, countries had reduced international flight operations, investment and commodity. Besides, labor trade was in a downturn. These changes had brought unprecedented impact to the global manufacturing supply chain. It was obvious that the COVID-19 had brought negative effects on international trade, service industries, manufacturing and supply chains, and many companies were facing bankruptcy and shortage of funds (Deng, 2020; Zhang et al., 2021). In the post-epidemic era, how to make use of the initiative of green finance is very important. Because in the economic recovery and transformation of enterprises, green finance can promote the green capital market to actively fight the epidemic and serve and support the real economy with shortage of funds (Li, 2020). As one of the forms of green finance, green credit can support the development of green supply chain. By implementing green credit, credit leverage can be used to limit the development of high-pollution and high-loss industries. It can also provide preferential credit policies for the development of green supply chain enterprises, such as providing more financial support for the technical research, product design, production and sales of the green supply chain industry (Zhou et al., 2020; Xu X. et al., 2020).

In addition to being affected by the COVID-19, there is currently another development issue. With the increase of the global population and the continuous expansion of economic scale, environmental problems caused by energy use have seriously affected the normal life of human beings. Therefore, how to achieve green development and sustainable development has become a research hotspot. The carbon dioxide emitted by humans in production and life is the main reason for the frequent occurrence of the greenhouse effect and extreme climates (Claudia and Sophie, 2019; 
Wang et al., 2020; Wang and Wang, 2020). Besides, curbing the growth of carbon emissions has become the consensus of all countries around the world. Countries have taken measures such as introducing carbon taxes, vigorously promoting clean energy, and shutting down or rectifying low-capacity and high-energyconsuming enterprises (Xu X. F. et al., 2020; Wang et al., 2020). Among them, carbon emission allowances and trading policies have become generally recognized important emission reduction mechanisms. The process is that the government issues certain carbon emission indicators or quotas to enterprises to limit how many tons of carbon dioxide they can emit each year. If the enterprises save energy and reduce emissions, the indicators are useless. After that, the remaining part can be sold on the carbon trading market; on the contrary, if the carbon emissions exceed the quota, the excess part must be bought in the market with money. As an important main body of production activities, companies not only need to bear the responsibility for climate change, but also face the dual requirements of the government to reduce emissions and increase profits. At this time, how to determine the best emission reduction level is of vital importance (Yang et al., 2017; Che and Zhang, 2021).

In order to explore the development of the green supply chain in the current environment, another new trend needs to be considered. With the rapid development of e-commerce, consumers' shopping habits are shifting from traditional offline shopping to online shopping. This change has put traditional distributors under unprecedented competitive pressure (Toyo, 2020; Li et al., 2021). At the same time, it also encourages manufacturers to maintain traditional retail channels while opening up online sales channels to directly obtain market information in order to occupy more market shares (Wang et al., 2020). For example, brand manufacturers such as Dell, Apple, Nike, Huawei, Xiaomi, Haier, etc., all use a dual-channel model that combines traditional offline wholesale sales channels and online direct sales channels to sell products (Benny et al., 2014; Julien et al., 2021). However, the incompatibility of decisionmaking goals between online and offline channels will lead to intensified conflicts, and there will be problems such as price competition and resource allocation. This is contrary to the original intention of forming an online and offline complementary collaboration channel model (Phoebe and Takashi, 2020; Li et al., 2021). Therefore, it is necessary to study the competition and behavior of participants in the dual-channel supply chain.

Based on the above background, this paper study the emission reduction strategy of the dual-channel supply chain. To differ from the previous literature, this paper not only considers the impact of the carbon trading mechanism on the profits and decision-making of manufacturers, but also considers that under the background of the epidemic, companies have insufficient funds to make green loans to financial institutions. By constructing a dual-channel supply chain model, to analyze the difference in profit and emission reduction of supply chain participants in the above two different situations. Specifically, we contribute to current knowledge in several directions. First, compared with the previous single channel research, we study the dual channel supply chain, which is more in line with the changes of supply chain under the background of internet development. Second, unlike previous studies that only considered one green financial measure, we considered the simultaneous occurrence of carbon trading and green loans. In the post-epidemic era, it is more realistic for companies to carry out these two measures at the same time in order to resume production. Finally, this paper constructs a Stackelberg game model with the manufacturer as the dominant player, and explores the influence of different situations on the supply chain emission reduction decision-making strategy under the manufacturer's leadership. This model broadens the research thinking of dual-channel supply chain under the background of green finance, and enriches related research theories.

The remainder of this paper is organized as follows. Related literature is reviewed in Literature Review. We gave a detailed description of research problem and model, and present our model assumptions in Problem Description and Model Hypotheses. In Model Analysis, We introduced two different situations and analyzed the model in detail according to the game sequence. We assign values to the parameters in the formula obtained after the model calculation, and complete the numerical simulation in Numerical Simulation. Finally, we present conclusions and put forward some management implications in Conclusion.

\section{LITERATURE REVIEW}

This paper focuses on the impact of different situations on dualchannel carbon emission reduction strategies when manufacturers participate in carbon trading or carbon trading and green finance loans are conducted at the same time. There are three streams of literature related to this work: dual-channel supply chain, green finance, and carbon trading. In this section, we will review the related literature and point out how our study differs from them.

\section{Dual-Channel Supply Chain}

In recent years, the dual-channel supply chain has attracted widespread attention in the literature of marketing and operations management. Related research mainly focuses on channel selection, pricing decisions, coordination and optimization. Kevin et al. (2003) analyzed the impact of manufacturers opening online direct sales channels on their traditional wholesale sales channels, and pointed out that the opening of direct sales channels is a strategy for improving the efficiency of traditional retail channels, which can prompt retailers to reduce retail prices. Even if the demand for direct sales channels is zero, manufacturers and retailers can still increase profits. Chen et al. (2012) studied the pricing strategies and coordination plans of manufacturers in the dual-channel supply chain, and found that the price contracts of supply chain participants can coordinate the dual-channel supply chain, and then benefit retailers. Ma et al. (2013) studied the influence of government subsidies on the pricing decision of a dual-channel supply chain based on the difference between consumers' preferences for online channels and traditional 
channels. Chen et al. (2017) studied the price and quality decision chain in dual-channel supply, and demonstrated the quality sensitivity parameters of different channels to price and product quality, as well as profit and consumer surplus, and proved that the introduction of new channels can achieve quality improvement. Yang et al. (2017) established four supply chain distribution models with different channel structures, analyzed the company's optimal pricing decisions, emission reduction decisions, and compared the optimal decisions of the models. Zhou et al. (2017), Zhou (2019) designed four types of dualchannel supply chain structures, considering the initial demand of physical channels and online channels, and defined the concept of the relative rate of customer channel preference. The selection strategy of supply chain channel structure based on the relative rate of customer channel preference is studied by manufacturers and physical retailers respectively as decision makers. By constructing a dual-channel supply chain decision-making model composed of manufacturers and retailers who have invested in innovation, Liang and Wei (2020) studied the impact of the government's simultaneous use of $\mathrm{R} \& \mathrm{D}$ subsidies and production subsidies on supply chain innovation, pricing and profits. Sun et al. (2020) studied the impact of different power structures on the prices, demand and revenue of members in a dual-channel supply chain which was composed of a manufacturer and a retailer. Che et al. (2021a) studied the emission reduction behaviors and profit differences of the participants in the dual-channel supply chain under different government subsidies.

\section{Green Finance in the Supply Chain}

So far, there are a considerable number of papers studying the impact of green finance on supply chain members. Huo et al. (2014) and Che et al. (2015) considered the impact of capital constraints and financing costs to study the coordination effect of supply chain contracts on the supply chain; Also, they analyzed the lending risks of banks and their influencing factors, and put forward conclusions which could provide references for banks to evaluate credit risks. Wang and Zhi (2016) demonstrated that green financial loans were a financial model resource that aimed at environmental protection and could improve the efficiency of the supply chain. Zhou et al. (2017) studied the game model between the government, banks and enterprises from the perspective of green credit and found that in the short term, government supervision could increase the enthusiasm of banks and enterprises to participate in the implementation of green supply chains. Besides, under the circumstances, banks would take the initiative to implement green credit, and enterprises would also take the initiative to implement green supply chain. Qin et al. (2018) took the implementation of a green supply chain by sellers in the downstream of the supply chain as a background, and studied the decision-making and benefits of implementing a green supply chain in the case of bank loans and cost sharing when their own emission reduction funds were insufficient. Zhou et al. (2020) used the secondary supply chain system of the new retail industry as the research background, and considered whether the manufacturer made green financial loans and additional government incentives. They studied the impact of green financing interest rates on the profits of participants and the manufacturers' emission reduction decisions. They found the carbon emission reduction level of the manufacturer and the optimal order quantity of the new retailer were inversely related to the green finance loan interest rate. Ding et al. (2020) found that green credit support could help strengthen the tendency to adopt decisions. The greater the green credit interest rate discount, the greater the financing ratio. Therefore, the supply chain could adopt higher-level carbon technologies to gain greater momentum. In addition, the internal cost sharing ratio of the supply chain could realize the dual optimization of investment income and the level of low-carbon technology adoption.

\section{Carbon Trading}

In order to deal with environmental pollution and global climate deterioration, governments of many countries have issued various policies and regulations. Among them, the carbon quota and trading mechanism is one of the earliest and most effective policies adopted by all countries (Huang et al., 2020). Through a three-stage game, Subramanian et al. (2007) gave a design method for manufacturers' optimal emission reduction investment, optimal output, and revenue-sharing contract in the context of carbon emission constraints and carbon trading mechanisms. Ma et al. (2014) divided suppliers and manufacturers into high-emission and low-emission enterprises, bought and sold carbon emission rights respectively. By using a hyper-network model to study the output, price, and overall benefits of the supply chain with and without carbon trading. Du (2015) researched a new supply chain composed of carbon emission rights suppliers and carbon emission rights dependent companies. They used the government-set carbon allowance as a variable parameter to introduce fairness preferences and social welfare, and studied the impact of carbon emissions on the profits of suppliers and demanders. Che et al. (2017a) and Tan et al. (2017) studied the supply chain coordination issues based on quantity discount contracts under different carbon emission rights trading policies. Besides, they compared them with the situation without carbon emission constraints. It was found that under different carbon emission rights trading policies, quantity discount contracts could achieve the coordination of the supply chain. And the optimal order quantity of the supply chain without carbon emission constraints was greater than the optimal order quantity of the supply chain of external carbon emission rights trading. Wang et al. (2018) considered the competition between ordinary manufacturers and lowcarbon manufacturers, and constructed supply chain decisionmaking models under centralized and decentralized models to solved emission reduction rates and product sales prices. They found that the implementation of the carbon trading mechanism reduced the total carbon emissions, but higher carbon trading prices would reduce the profits of the supply chain. The improvement of consumer price sensitivity made the profits of ordinary manufacturers, low-carbon manufacturers, retailers and the whole supply chain lower. 
Huang et al. (2020) constructed a Stackelberg game model of two-level supply chain dominated by manufacturers. By introducing the emission reduction cost sharing mechanism, the optimal solutions of decentralized decision-making and centralized decision-making were given respectively, which realized the supply chain coordination and pareto improvement of profits of supply chain members.

By reviewing the above literature, we know that scholars have done a lot of research on the three aspects of dualchannel supply chain, green finance in the supply chain, and carbon trading in the supply chain. However, the existing research on emission reduction in the dual-channel supply chain mainly explores pricing decisions, optimal decisions under government subsidies, and participant cooperation, and rarely considers the shortage of funds for manufacturers. In addition, the research on green finance in the supply chain mostly studies the decision-making behavior of the supply chain under a single channel, and seldom studies the situation of the dual-channel supply chain. The supply chain research under carbon trading is mostly about government mechanism and channel selection, and there are few researches about the shortage of funds and dual channels. Therefore, based on the above research and practice background, under the background of low-carbon emission reduction and the economic recovery needs of enterprises in the post epidemic era, this paper comprehensively considers the carbon trading mechanism and green financial loans, constructs a dual channel supply chain decision-making model, and analyzes the pricing decisions and emission reduction strategies among members in two different situations.

\section{PROBLEM DESCRIPTION AND MODEL HYPOTHESES}

\section{Problem Description}

In order to explore the dual-channel supply chain emission reduction strategy considering green finance, this paper constructs a dual-channel supply chain decision-making model with the manufacturer as the leader of Stakelberg and the retailer as the follower. Nowadays, many manufacturing factories have their own online direct sales platform stores. In the dual-channel supply chain of this paper, manufacturers can choose traditional retail methods to wholesale goods to retail stores for offline sales, while manufacturers can also choose to sell directly to consumers online.

By constructing this model, this paper focuses on the effect of different situations on the profits of supply chain participants and low carbon emission reduction in a dual-channel where manufacturers participate in carbon trading and make green financial loans. The dual-channel supply chain model is shown in Figure 1.

\section{Model Hypotheses}

According to the dual-channel supply chain model, there are some assumptions.

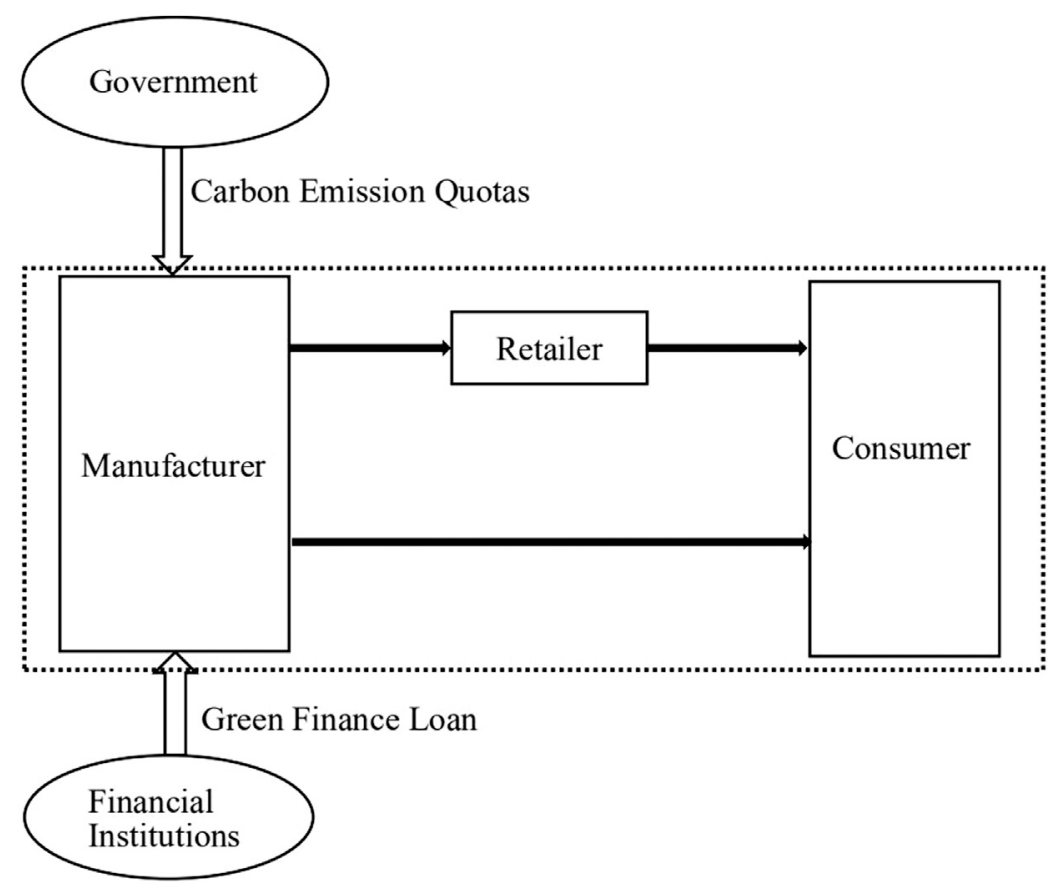

FIGURE 1 | Dual-Channel supply chain model. 
Assumption 1: To obtain the demand function of dualchannel supply chain, we adopt the framework established by Li et al. (2019) and Che et al. (2021a) as follows:

$$
\begin{gathered}
D_{r}=\theta A-p_{i}^{r}+\beta p_{i}^{m}+k e_{i} \\
D_{m}=(1-\theta) A-p_{i}^{m}+\beta p_{i}^{r}+k e_{i}
\end{gathered}
$$

The demand functions imply that demand is negatively correlated with sales price, and positively correlated with the low-carbon degree of the product. Consumers are willing to buy lower carbon products at higher prices. Besides, there is a price competition between traditional sales channel and online sales channel. In the functions, $D_{r}$ represents the demand of traditional retailer channel. $D_{m}$ represents the demand of online channel, and $A$ is the potential market scale. $\theta \quad(0 \leq \theta \leq 1)$ represents the market share of traditional retailer channel, and $1-\theta$ is the market share occupied by online sales channel. $\beta$ represents the cross-price elasticity coefficient of traditional channels and online channels

$(0 \leq \beta \leq 1)$. $k$ represents the level of consumer environmental awareness $(0 \leq k \leq 1)$. $e$ is the carbon emission per unit product before emission reduction. $e_{i}$ represents the manufacturer's emission reduction in different situations. $p_{i}^{r}$ is the product price of traditional retailer channel and $p_{i}^{m}$ is the product price of online channel. When $i=1$, manufacturers conduct carbon trading; When $i=2$, manufacturers conduct carbon trading and make green financial loans.

Assumption 2: Under the carbon trading mechanism, the government allocates certain carbon allowances to manufacturers by accounting for their historical carbon emissions, denoted by $Q$. When the total carbon emission exceeds the carbon quota, the manufacturer can buy the quota from the carbon trading market at a unit carbon price to offset the excess. Unit carbon price is represented by $p_{c}$. Conversely, if the manufacturer's total carbon emissions are lower than the carbon quota, the manufacturer can sell the excess quota on the market at a unit carbon price to obtain revenue.

Assumption 3: The manufacturer's initial capital is $B$, and the manufacturer's initial capital required to support the optimal production volume of the dual-channel supply chain is $\bar{B}=c\left(D_{r}+D_{m}\right)$. When $B<\bar{B}$, the manufacturer applies for a

\begin{tabular}{ll}
\hline TABLE 1 | Notations. & \\
\hline Parameters & \\
\hline$D_{r}$ & \multicolumn{1}{c}{ Definition } \\
$D_{m}$ & Demand of traditional retail channels \\
$A$ & Demand of online sales channels \\
$\theta$ & Market scale \\
$p_{i}^{r}$ & Market share of traditional retail channels \\
$p_{i}^{m}$ & Product price of traditional retail channels \\
$\beta$ & Product price of online sales channels \\
$k$ & Cross price elasticity factor \\
$e_{i}$ & Consumer environmental awareness level \\
$w_{i}$ & Emission reduction \\
$e$ & Wholesale prices \\
$Q$ & Original product carbon emissions \\
$p_{c}$ & Carbon quota \\
$c$ & Carbon trading price \\
$r$ & Cost \\
$R$ & Rate \\
$B$ & Financing costs \\
& Initial capital \\
\end{tabular}

green financial loan from a financial institution. The loan interest rate is denoted by $r$. So the manufacturer's financing cost is $R=r\left[c\left(D_{r}+D_{m}\right)-B\right]$.

Assumption 4: The cost of carbon abatement for the manufacturer is $1 / 2 I e_{i}^{2}, I$ represents the manufacturer's abatement cost coefficient. Refer to Chen et al. (2019) and Xu et al. (2019a), when the investment in emission reduction is increased, the cost of carbon emission reduction input and the emission reduction amount have a quadratic relationship. The manufacturer's unit manufacturing cost remains unchanged, and the raw material procurement cost is the main focus, and other costs are not considered for the time being. Table 1 summarizes all the parameters and their definitions involved in this paper.

\section{MODEL ANALYSIS}

\section{Supply Chain Emission Reduction Decisions Under the Carbon Trading Mechanism}

Under the carbon trading mechanism, the government first determines the amount of carbon emissions given to the manufacturer, then the manufacturer determines the emission reduction, wholesale price $\left(w_{i}\right)$, online price, and finally the retailer determines the sales price of traditional channels. As shown in Figure 2, in the dual-channel supply chain, the manufacturer is the leader, making decisions first from the perspective of profit maximization, and then the retailer makes the most beneficial decision on the basis of the manufacturer's decision. In the process of decision-making, the information of both parties is transparent and symmetrical.

So the profits of the manufacturer and the retailer are:

$$
\begin{gathered}
\pi_{1}^{m}=w_{1} D_{r}+p_{1}^{m} D_{m}-\frac{1}{2} I e_{1}^{2}-p_{c}\left[\left(e-e_{1}\right)\left(D_{r}+D_{m}\right)-Q\right] \\
\pi_{1}^{r}=\left(p_{1}^{r}-w_{1}\right) D_{r}
\end{gathered}
$$

Substituting formulas (1) and (2) into formulas (3) and (4), the decision models are:

$$
\begin{gathered}
\pi_{1}^{m}=w_{1}\left(\theta A-p_{1}^{r}+\beta p_{1}^{m}+k e_{1}\right)+p_{1}^{m}\left[(1-\theta) A-p_{1}^{m}+\beta p_{1}^{r}+k e_{1}\right] \\
-\frac{1}{2} I e_{1}^{2}-p_{c}\left[\left(e-e_{1}\right)\left(A-p_{1}^{r}-p_{1}^{m}+\beta p_{1}^{m}+\beta p_{1}^{r}+2 k e_{1}\right)-Q\right] \\
\pi_{1}^{r}=\left(p_{1}^{r}-w_{1}\right)\left(\theta A-p_{1}^{r}+\beta p_{1}^{m}+k e_{1}\right)
\end{gathered}
$$

Then solve them by reverse induction. First of all, find the second derivative of $\pi_{1}^{r}$ with respect to $p_{1}^{r}$, then get $\frac{\partial^{2} \pi_{1}^{r}}{\partial p_{1}^{r^{2}}}=-2<0$. So $\pi_{1}^{r}$ is a strictly concave function of $p_{1}^{r}$, there is an optimal solution. Furthermore, by finding the first derivative of $\pi_{1}^{r}$ with respect to $p_{1}^{r}$ and making it equal to 0 , the optimal response function of $p_{1}^{r}$ with respect to $e_{1}, w_{1}, p_{1}^{m}$ is obtained.

$$
\begin{gathered}
\frac{\partial \pi_{1}^{r}}{\partial p_{1}^{r}}=\theta A-2 p_{1}^{r}+\beta p_{1}^{m}+k e_{1}+w_{1} \\
p_{1}^{r}\left(e_{1}, w_{1}, p_{1}^{m}\right)=\frac{\theta A+\beta p_{1}^{m}+k e_{1}+w_{1}}{2}
\end{gathered}
$$

Substitute formulas (8) into formulas (5) and get: 


$$
\begin{gathered}
\pi_{1}^{m}=w_{1}\left(\frac{1}{2} \theta A-\frac{1}{2} w_{1}+\frac{1}{2} \beta p_{1}^{m}+\frac{1}{2} k e_{1}\right)-\frac{1}{2} I e^{2}-p_{1}^{m}\left[p_{1}^{m}-k e_{1}\right. \\
-\beta\left(\frac{1}{2} w_{1}+\frac{\beta p_{1}^{m}}{2}+\frac{1}{2} k e_{1}+\frac{\theta A}{2}+A(\theta-1)\right]+p_{c}\left\{Q-\left(e-e_{1}\right)\right. \\
\left.\left[A-p_{1}^{m}-\frac{1}{2} w_{1}+\frac{\beta p_{1}^{m}}{2}-\frac{\theta A}{2}+\frac{3 k e_{1}}{2}+\beta\left(\frac{1}{2} w_{1}+\frac{\beta p_{1}^{m}}{2}+\frac{\theta A}{2}+\frac{k e_{1}}{2}\right)\right]\right\}
\end{gathered}
$$

In order to obtain the Hessian matrix of the manufacturer's profit function with respect to $w_{1}, p_{1}^{m}$, further formula (9) is used to calculate.

$$
\begin{gathered}
\frac{\partial^{2} \pi_{1}^{m}}{\partial w_{1}^{2}}=-1, \frac{\partial^{2} \pi_{1}^{m}}{\partial p_{1}^{m^{2}}}=\beta^{2}-2, \\
\frac{\partial^{2} \pi_{1}^{m}}{\partial w_{1} p_{1}^{m}}=\beta, \frac{\partial^{2} \pi_{1}^{m}}{\partial p_{1}^{m} w_{1}}=\beta,
\end{gathered}
$$

So the Hessian matrix of the manufacturer's profit function with respect to $w_{1}, p_{1}^{m}$ is:

$$
H\left(\pi_{1}^{m}\right)=\left[\begin{array}{lr}
-1 & \beta \\
\beta & \beta^{2}-2
\end{array}\right]
$$

In this Hessian matrix, the first-order principal is negative, and $\left|H\left(\pi_{1}^{m}\right)\right|=2\left(1-\beta^{2}\right)>0$. So $\pi_{1}^{r}$ is a strictly concave function of $w_{1}$ and $p_{1}^{m}$, there is an optimal solution. Furthermore, to find the first derivative of $\pi_{1}^{m}$ with respect to $w_{1}, p_{1}^{m}$ and make it equal to 0 . After the combination, the optimal inverse function of $\pi_{1}^{m}$ with respect to $w_{1}, p_{1}^{m}$ can be obtained.

$$
\begin{gathered}
\frac{\partial \pi_{1}^{m}}{\partial p_{1}^{m}}=k e_{1}+p_{1}^{m}\left(\frac{\beta^{2}}{2}-2\right)+\beta\left(w_{1}+\frac{\beta p_{1}^{m}}{2}+\frac{\theta A}{2}+\frac{k e_{1}}{2}\right) \\
-A(\theta-1)-p_{c}\left(e-e_{1}\right)\left(\frac{\beta^{2}}{2}+\frac{\beta}{2}-1\right) \\
\frac{\partial \pi_{1}^{m}}{\partial w_{1}}=\beta p_{1}^{m}-w_{1}+\frac{\theta A}{2}+\frac{k e_{1}}{2}-p_{c}\left(\frac{\beta}{2}-\frac{1}{2}\right)\left(e-e_{1}\right) \\
w_{1}^{*}\left(e_{1}\right)=\frac{-\left(\beta A+e p_{c}-p_{c} e_{1}+A \theta+k e_{1}\right.}{2\left(\beta^{2}-1\right)} \\
p_{1}^{m *}\left(e_{1}\right)=\frac{-\left(A+\beta e_{1} k-e \beta_{c}-p_{c} e_{1}-A \theta+k e_{c} e_{1}\right)}{2\left(\beta^{2}-1\right)}
\end{gathered}
$$

Substitute formulas (12) and (13) into formulas (8) and get the optimal response function of $p_{1}^{r}$ with respect to $e_{1}$ :

$p_{1}^{r *}\left(e_{1}\right)$

$$
=\frac{-\left(\begin{array}{l}
2 \beta A+e p_{c}-p_{c} e_{1}+3 \theta A+3 k e_{1}+e \beta p_{c}-e_{1} \beta p_{c}-2 \theta A \beta \\
+2 \beta k e_{1}-e \beta^{2} p_{c}-e \beta^{3} p_{c}+\beta^{2} p_{c} e_{1}+e_{1} \beta^{3} p_{c}-\theta A \beta^{2}-\beta^{2} k e_{1}
\end{array}\right)}{\left(4 \beta^{2}-4\right)}
$$

Substitute formulas (13) and (14) into formulas (1) and (2) and get dual-channel optimal demand function:

$$
\begin{gathered}
D_{1}^{r *}=\frac{p_{c}\left(e_{1}-e+e \beta-\beta e_{1}\right)+\theta A+k e_{1}}{4} \\
D_{m}^{1 *}=\frac{2\left(A-e p_{c}+p_{c} e_{1}-\theta A+k e_{1}\right)+e \beta p_{c}-\beta p_{c} e_{1}}{4} \\
+\frac{A \beta \theta+k e_{1} \beta+e \beta^{2} p_{c}-\beta^{2} p_{c} e_{1}}{4}
\end{gathered}
$$

\section{Supply Chain Emission Reduction Decisions Under Carbon Trading and Green Finance Loans}

Considering the lack of funds, manufacturers apply for green finance loan financing from financial institutions, and repay the loans by selling products and carbon emission rights. Under the situation, the government first determines the amount of carbon emissions given to the manufacturer, then financial institutions determine loan interest rates, then the manufacturer determines the emission reduction, wholesale price, online price, and finally the retailer determines the sales price of traditional channels. As it is shown in Figure 3.

So the profits of the manufacturer and the retailer are:

$$
\begin{gathered}
\pi_{2}^{m}=w_{2} D_{r}+p_{2}^{m} D_{m}-\frac{1}{2} I e_{2}^{2} \\
-p_{c}\left[\left(e-e_{2}\right)\left(D_{r}+D_{m}\right)-Q\right]-r\left[c\left(D_{r}+D_{m}\right)-B\right] \\
\pi_{2}^{r}=\left(p_{2}^{r}-w_{2}\right) D_{r}
\end{gathered}
$$

Substitute formulas (1) and (2) into formulas (17) and (18) and get:

$$
\begin{gathered}
\pi_{2}^{m}=w_{2}\left(A \theta-p_{2}^{r}+\beta p_{2}^{m}+k e_{2}\right)-\frac{1}{2} I e_{2}^{2}+p_{2}^{m}\left(A-p_{2}^{m}\right. \\
\left.-A \theta+k e_{2}+\beta p_{2}^{r}\right)-r\left(A c-B-c p_{2}^{m}-c p_{2}^{r}+c \beta p_{2}^{m}+2 k e_{2} c+c \beta p_{2}^{r}\right) \\
+p_{c}\left(Q-\left(e-e_{2}\right)\left(A-p_{2}^{m}-p_{2}^{r}+\beta p_{2}^{m}+2 k e_{2}+\beta p_{2}^{r}\right)\right)
\end{gathered}
$$

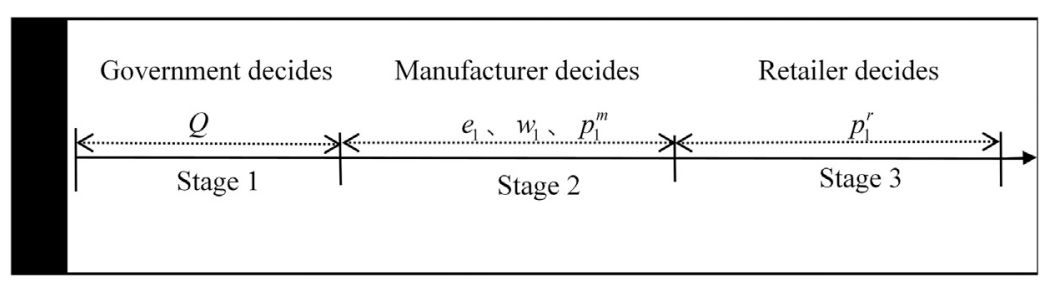

FIGURE 2 | The first decision sequence diagram ecision sequence diagram. 


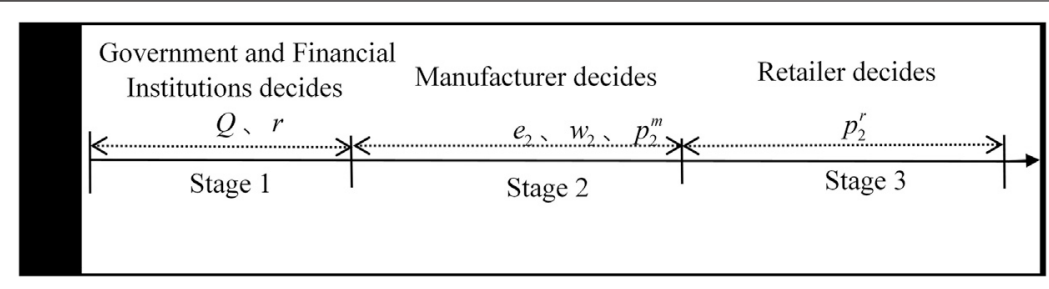

FIGURE 3 | The second decision sequence diagram.

$$
\pi_{2}^{r}=\left(p_{2}^{r}-w_{2}\right)\left(\theta A-p_{2}^{r}+\beta p_{2}^{m}+k e_{2}\right)
$$

Then solve them by reverse induction. First of all, find the second derivative of $\pi_{2}^{r}$ with respect to $p_{2}^{r}$, then get $\frac{\partial^{2} \pi_{2}^{r}}{\partial r^{2}}=-2<0$. So $\pi_{2}^{r}$ is a strictly concave function of $p_{2}^{r}$, there is an optimal solution. Furthermore, by finding the first derivative of $\pi_{2}^{r}$ with respect to $p_{2}^{r}$ and making it equal to 0 , the optimal response function of $p_{2}^{r}$ with respect to $e_{2}, w_{2}, p_{2}^{m}$ is obtained

$$
\begin{gathered}
\frac{\partial \pi_{2}^{r}}{\partial p_{2}^{r}}=\theta A-2 p_{2}^{r}+\beta p_{2}^{m}+k e_{2}+w_{2} \\
p_{2}^{r}\left(e_{2}, w_{2}, p_{2}^{m}\right)=\frac{\theta A+\beta p_{2}^{m}+k e_{2}+w_{2}}{2}
\end{gathered}
$$

Substitute formulas (22) into formulas (19) and get:

$$
\begin{gathered}
\pi_{2}^{m}=p_{2}^{m}\left(A-p_{2}^{m}-A \theta+e_{2} k+\frac{\beta w_{2}+\beta^{2} p_{2}^{m}+A \theta \beta+\beta e_{2} k}{2}\right) \\
-r\left(A c-B-c p_{2}^{m}+\frac{\beta c p_{2}^{m}+3 c e_{2} k+\beta c w_{2}}{2}+\frac{\beta^{2} c p_{2}^{m}+A \beta c \theta+\beta c e_{2} k}{2}\right. \\
\left.-\frac{c w_{2}+A c \theta}{2}\right)-\frac{1}{2} I e_{2}^{2}+w_{2}\left(\frac{A \theta-w_{2}+\beta p_{2}^{m}+e_{2} k}{2}\right)+p_{c}[Q-(e \\
\left.-e_{2}\right)\left(A-p_{2}^{m}+\frac{\beta p_{2}^{m}+3 e_{2} k+\beta w_{2}}{2}+\frac{\beta^{2} p_{2}^{m}+A \beta \theta+\beta e_{2} k}{2}\right. \\
\left.\left.-\frac{w_{2}+A \theta}{2}\right)\right]
\end{gathered}
$$

In order to obtain the Hessian matrix of the manufacturer's profit function with respect to $w_{2}, p_{2}^{m}$, further formula (23) is used to calculate.

$$
\begin{gathered}
\frac{\partial^{2} \pi_{2}^{m}}{\partial w_{2}^{2}}=-1, \frac{\partial^{2} \pi_{2}^{m}}{\partial p_{2}^{m^{2}}}=\beta^{2}-2, \\
\frac{\partial^{2} \pi_{2}^{m}}{\partial w_{1} p_{2}^{m}}=\beta, \frac{\partial^{2} \pi_{2}^{m}}{\partial p_{2}^{m} w_{2}}=\beta,
\end{gathered}
$$

So the Hessian matrix of the manufacturer's profit function with respect to $w_{2}, p_{2}^{m}$ is:

$$
H\left(\pi_{2}^{m}\right)=\left[\begin{array}{ll}
-1 & \beta \\
\beta & \beta^{2}-2
\end{array}\right]
$$

In this Hessian matrix, the first-order principal is negative, and $\left|H\left(\pi_{2}^{m}\right)\right|=2\left(1-\beta^{2}\right)>0$. So $\pi_{2}^{r}$ is a strictly concave function of $w_{2}$ and $p_{2}^{m}$, there is an optimal solution. Furthermore, to find the first derivative of $\pi_{2}^{m}$ with respect to $w_{2}, p_{2}^{m}$ and make it equal to 0 . After the combination, the optimal inverse function of $\pi_{2}^{m}$ with respect to $w_{2}, p_{2}^{m}$ can be obtained.

$$
w_{2}^{*}=\frac{\begin{array}{c}
-\left(A \beta-p_{c} e_{2}+A \theta+r c+e_{2} k+p_{c} e-A \beta \theta+\beta e_{2} k\right. \\
\left.-p_{c} e \beta^{2}+p_{c} \beta^{2} e_{2}-r \beta^{2} c\right)
\end{array}}{2\left(\beta^{2}-1\right)}+\begin{gathered}
-\left(A-p_{c} e_{2}-\theta A+r c+e_{2} k+p_{c} e+A \theta \beta+e_{2} k \beta\right. \\
p_{2}^{m_{*}} *=\frac{\left.-p_{c} e \beta^{2}+p_{c} \beta^{2} e_{2}-r c \beta^{2}\right)}{2\left(\beta^{2}-1\right)}
\end{gathered}
$$

Substitute formulas (24) and (25) into formulas (22) and get the optimal response function of $p_{2}^{r}$ with respect to $e_{2}$ :

$$
p_{2}^{r *}=\frac{\begin{array}{c}
-\left(2 \beta A-p_{c} e_{2}+3 \theta A+r c+3 e_{2} k+p_{c} e+p_{c} e \beta-p_{c} e_{2} \beta\right. \\
-2 \beta \theta A+r \beta c+2 \beta e_{2} k-p_{c} c \beta^{2}-p_{c} e \beta^{3}+p_{c} e_{2} \beta^{2} \\
\left.+p_{c} e_{2} \beta^{3}-\theta A \beta^{2}-r \beta^{2} c-r \beta^{3} c-\beta^{2} e_{2} k\right)
\end{array}}{4\left(\beta^{2}-1\right)}
$$

Substitute formulas (25) and (26) into formulas (1) and (2) and get dual-channel optimal demand function:

$$
\begin{gathered}
D_{r}^{2 *}=\frac{p_{c} e_{2}+\theta A-r c+k e_{2}-p_{c} e+\beta p_{c} e-p_{c} \beta e_{2}+r \beta c}{4} \\
D_{m}^{2 *}=\frac{A+p_{c} e_{2}-\theta A-r c+k e_{2}-p_{c} e}{2}+ \\
\frac{p_{c} e \beta-p_{c} \beta e_{2}+\theta A \beta+r \beta c+\beta k e_{2}+\beta^{2} p_{c} e-\beta^{2} p_{c} e_{2}+r \beta^{2} c}{4}
\end{gathered}
$$

\section{NUMERICAL SIMULATION}

In order to better verify the change relationship between the variables, this section will compare and analyze them through numerical examples. First, as shown in the description of each parameter in Problem Description and Model Hypotheses, the nature and scale of the research object are presented. Then, based on these description, we refer to the previous related literature (Yang et al., 2017; He et al., 2020; Wang et al., 2020; Liao et al., 


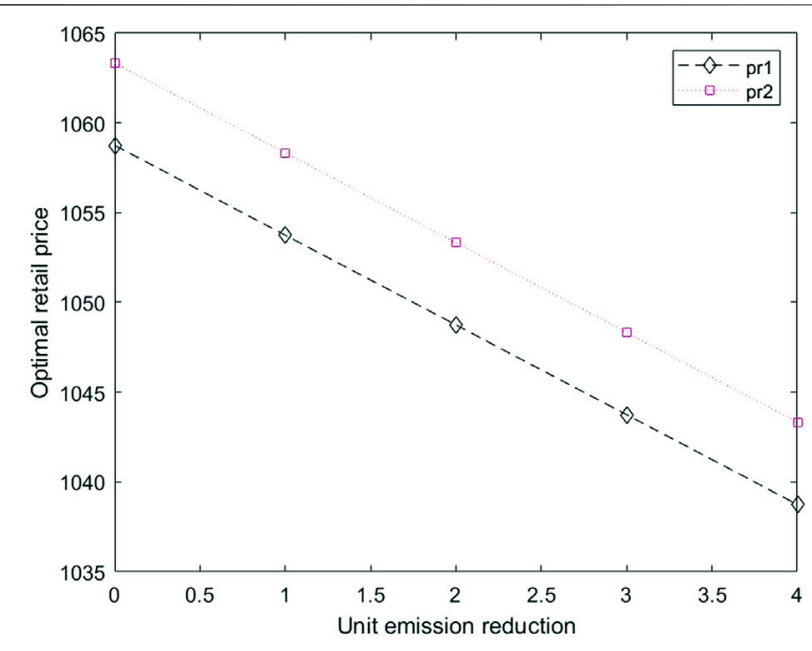

FIGURE 4 | Retailer price comparison chart.

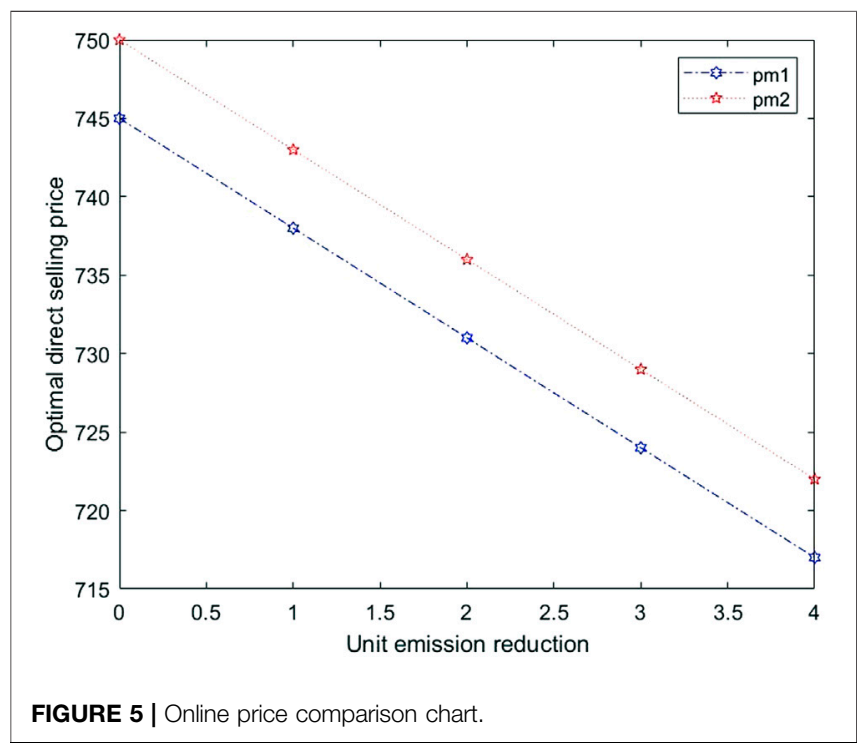

2021) and set the values of the fixed parameters. The values are as follows:

$$
\begin{aligned}
& p_{c}=15, r=0.05, k=0.5, \beta=0.5, \theta=0.6 \\
& A=1500, e_{i}=[0,4], e=6, Q=1000, c=200, B=10000
\end{aligned}
$$

\section{The Impact of Emission Reductions on Prices}

Through numerical simulation, the impact of emission reductions on various prices can be more clearly presented. Under the carbon trading mechanism,

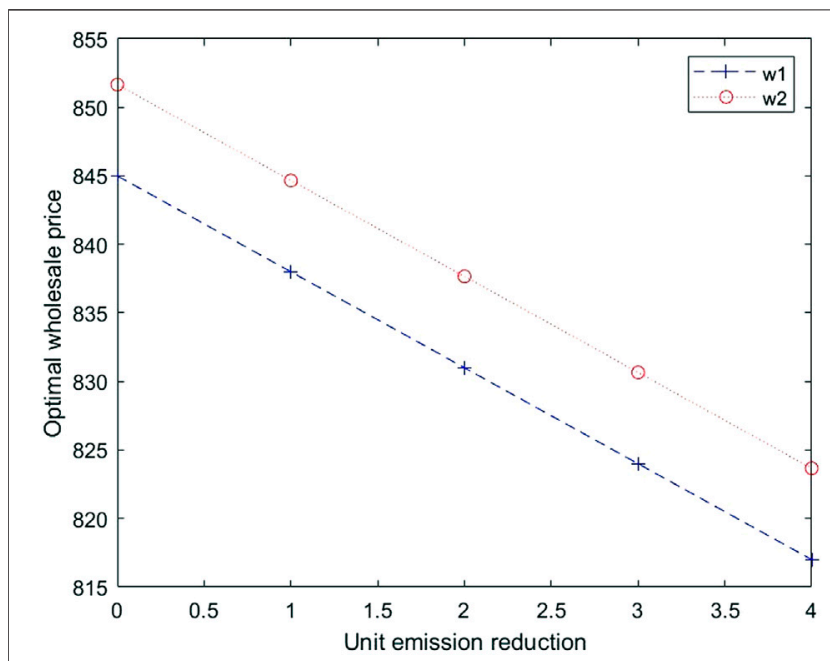

FIGURE 6 | Wholesale price comparison chart.

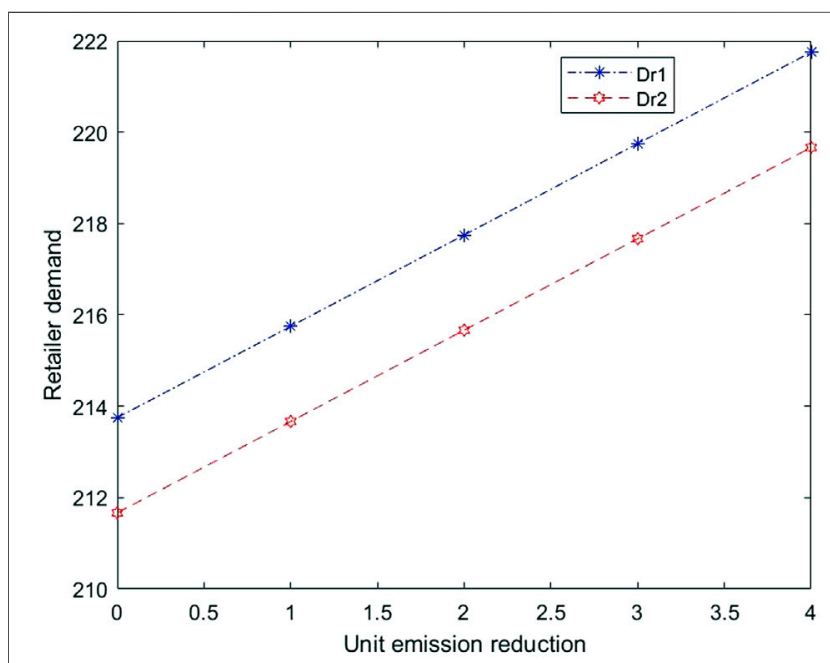

FIGURE 7 | Retailer demand comparison chart.

substitute the values into formula (12) to obtain the wholesale price. Substitute the values into formula (13) and (14) to get the online price and retail price. Similarly, When carbon trading and green finance loans happen simultaneously, substitute the values into formula (24) to obtain the wholesale price. Substitute the values into formula (25) and (26) to get the online price and retail price. As shown in Figures 4, 5, manufacturers' online prices and retailers' prices vary with emission reductions. It can be seen from the figures that as emission reductions increase, retailers' prices continue to fall, and manufacturers' online direct sales prices also continue to fall. As shown in Figure 6, wholesale prices vary with emission reductions. It can be seen from the figure that as emission reductions increase, 


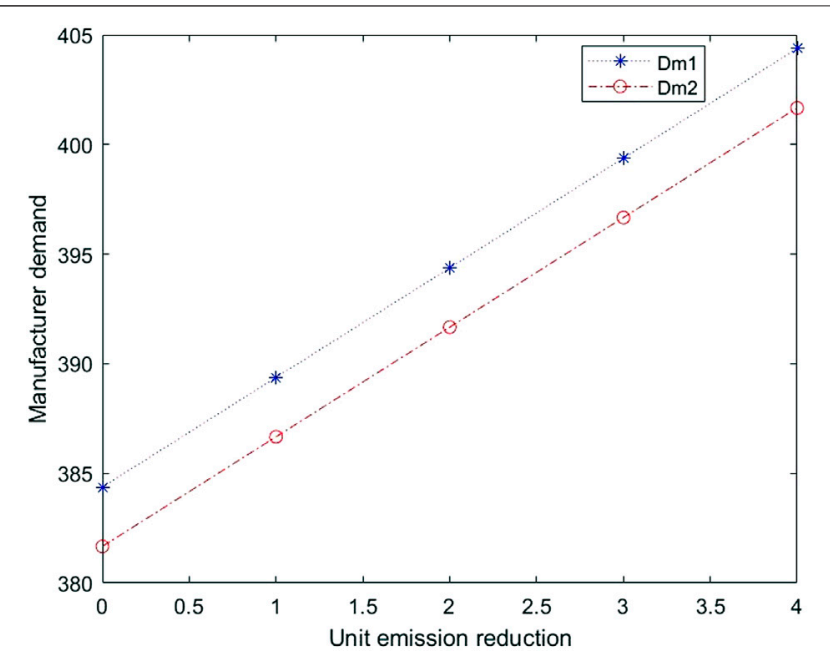

FIGURE 8 | Manufacturer demand comparison chart.

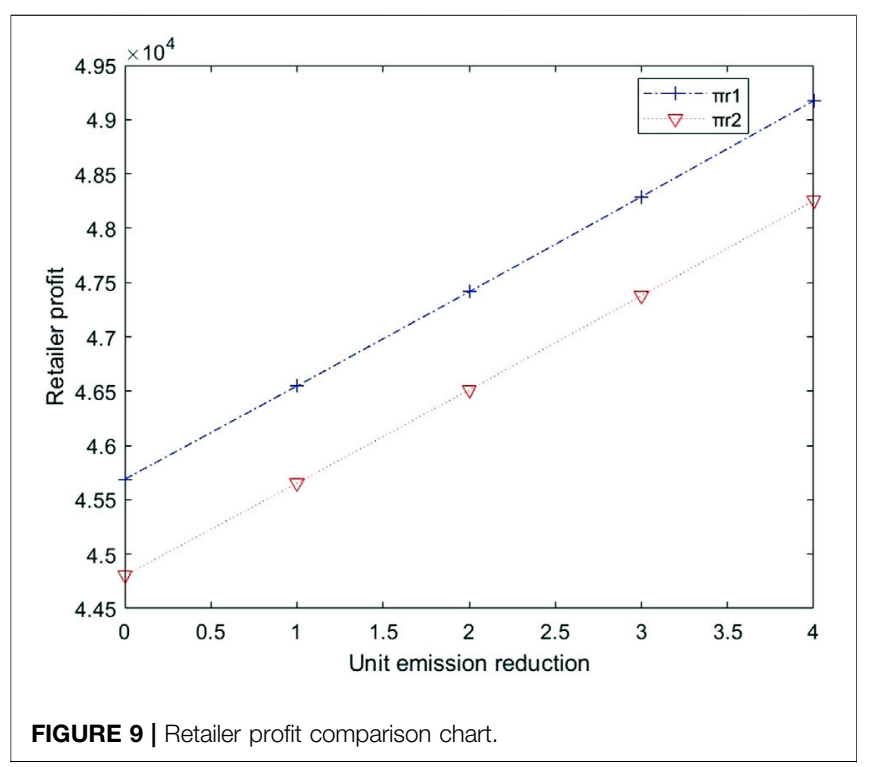

manufacturers' wholesale prices continue to fall, and they are in an inverse relationship.

\section{The Impact of Emission Reductions on Dual-Channel Demand}

Under the carbon trading mechanism, substitute the values into formula (15) and (16) to obtain the market demand for online and offline channels. When carbon trading and green finance loans happen simultaneously, substitute the values into formula (27) and (28) to obtain dual-channel demand. As shown in Figures 7, 8, dual-channel demands vary with emission reductions. It can be seen from the figures that with the increase of emission reductions, the market demand of online sales channels and offline sales channels will increase, so emission reductions and demand are positively related.

\section{The Impact of Emission Reductions on Dual Channel Profits}

On the basis of completing the above numerical substitution, we get the values of $w_{1}^{*}, p_{1}^{r *}, p_{1}^{m *}, D_{r}^{1 *}, D_{m}^{1 *}$ in different situations. Then calculate the profit of the manufacturer and the retailer. Under the carbon trading mechanism, substitute the values into formula (3) to obtain the profit of the manufacturer. Also, substitute the values into formula (4) to obtain the profit of the retailer. When carbon trading and green finance loans happen simultaneously, substitute the values into formula (17) to get the profit of the manufacturer. In the same way, substitute the values into formula (18) to obtain the profit of the retailer. As shown in Figures 9, 10, the profits of the manufacturer and the retailer vary with emission reductions. It can be seen from the figures that as emission reductions increase, the profit of manufacturer and the retailer increase, therefore emission reductions and profits have a positive relationship.

\section{CONCLUSION}

In this study, we construct a dual-channel green supply chain model to analyze the impact of different situations on the profits of participants and the manufacturers' emission reduction decisions. Building on the literature on dual-channel supply chain (Yang et al., 2017; Wang et al., 2020; Che et al., 2021b), our dual-channel supply chain model consists of a manufacturer and a retailer, and is divided into online and offline channels. Consistent with these literature, we find that manufacturers' carbon emission reductions will affect profits and pricing. In order to maximize profits, manufacturers need to constantly adjust their carbon emissions. Through the model calculation and analysis, the results show that:

1. Under the carbon trading mechanism, as manufacturers'emission reductions continue to increase, in order to reach the overall optimal level of the supply chain, manufacturers' wholesale prices, online prices, and retail sales prices will drop accordingly. However, the demand for the dual-channel also increases, and ultimately the profits of manufacturers and retailers also increase.

2. When the manufacturer is conducting carbon trading and green financial loans at the same time, as the manufacturer's emission reductions continue to increase, the manufacturer's insufficient funds need to make a green loan from a financial institution, and the profit is lower than when the loan is not available. But it is still a growing trend.

3. In the case that the manufacturer is conducting carbon trading and green financial loans at the same time, as the manufacturer's emission reductions continue to increase, in order to reach the overall optimal level of the supply chain, the manufacturer's wholesale price, online price and retail sales price will drop, and the demand for the dual channels will increase.

Previous studies only consider the occurrence of carbon trading, and found that as the level of emission reduction 


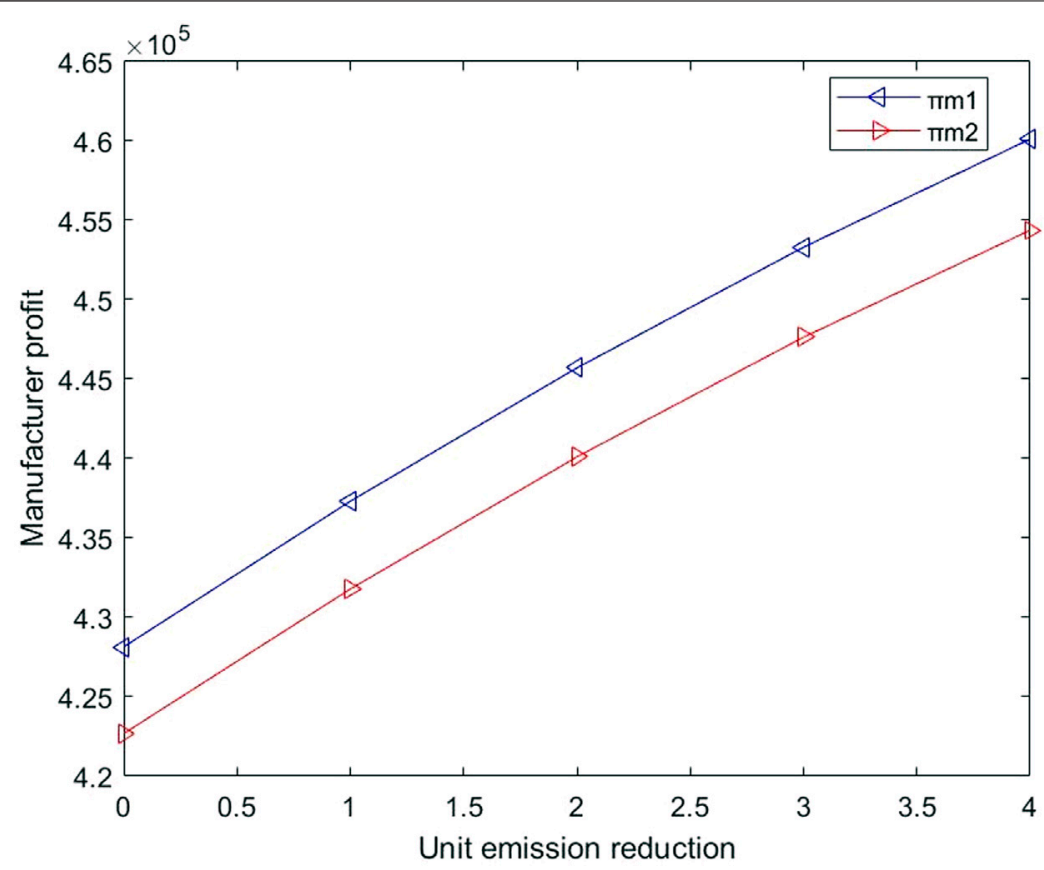

FIGURE 10 | Manufacturer's profit comparison chart.

increases, both wholesale and retail prices will fall, but sales will rise, which will increase the final profit (Miu et al., 2020; Che et al., 2021a). These findings are consistent with our conclusions (1) and (2), which shows that our model is effective. To differ from the previous literature, under the background of the current national control of enterprise carbon emissions and limited enterprise funds, based on the existing literature on carbon trading and green finance (Zhou et al., 2017; Qin et al., 2018; Huang et al., 2020), this study considers the simultaneous occurrence of carbon trading and green financial loans in the second scenario, which reveals how manufacturers should adjust their emission reduction strategies when their funds are insufficient.

Based on the above research conclusions, the following management enlightenment is put forward. For manufacturers, it is very important to take an objective and rational view of participating in the carbon trading market and improving the level of low-carbon emissions reduction (Xu et al., 2019b; Che et al., 2020) Companies participating in carbon rights trading in the carbon trading market can not only increase profits by strengthening emission reductions, but also conform to the current trend of low-carbon emission reduction, fulfill more corporate social responsibilities, and improve corporate image. When operating funds are insufficient, companies can lend to financial institutions. Although a part of the financing cost is increased, from an overall perspective, financing can maintain the normal operation of the company, and as emission reductions increase, the company's profits will also increase (Che et al., 2017b). In addition to traditional wholesale and retail, companies can also establish their own online direct sales platform under the background of the Internet to increase sales revenue by opening up new channels. At the same time, they must pay attention to the price competition between the two channels and maintain the relationship between the two.

For the government, in response to the country's call for lowcarbon emissions reduction, it should improve the relevant mechanisms of the carbon trading market and prepare for the full coverage of carbon trading pilots. Nowadays, the operating rules and acceptance of carbon trading by enterprises still need to be improved, and the government should strengthen publicity and popularization. In addition, the government should implement a fair and diverse allocation plan when formulating carbon allowances for different companies. It is not only based on the company's annual carbon emissions, but also can be the size of the company, its low-carbon environmental protection image, and its main business type. In terms of green financial loans, companies can try to cooperate with financial institutions to subsidize green financial loan projects to allow institutions to reduce loan interest rates to a certain extent, thereby reducing the pressure on low-carbon emission reduction financing. At the same time, it is necessary to strengthen supervision to ensure that the funds obtained from corporate green financial loans are really invested in low-carbon emission reduction production.

There are some limitations in this research. First, this paper does not consider retailers' participation in low-carbon emission reduction, but only considers manufacturers' reduction of carbon emissions during the production process. Future research can consider retailers' marketing efforts on lowcarbon products, and the government can also give retailers certain incentives and support policies. In addition, only manufacturers and retailers are considered in this game, and 
the government or financial institutions are not included. Further studies can also try to make game players more diverse.

\section{DATA AVAILABILITY STATEMENT}

The original contributions presented in the study are included in the article/Supplementary Material, further inquiries can be directed to the corresponding author.

\section{AUTHOR CONTRIBUTIONS}

All authors contributed to the study conception, design, read, and approved the final manuscript.

\section{REFERENCES}

Benny, M., Harish, K., and Tirtha, D. (2014). The Strategic Role of Third-Party Marketplaces in Retailing. Prod. Operations Manag. 23 (11), 1937-1949. doi:10. 1111/poms.12203

Che, C., Chen, Y., Zhang, X., and Zhang, Z. (2021a). The Impact of Different Government Subsidy Methods on Low-Carbon Emission Reduction Strategies in Dual-Channel Supply Chain. Complexity 2021 (9), 1-9. doi:10.1155/2021/ 6668243

Che, C., Luo, W. P., and Qi, X. L. (2017a). The Influence of Space and Social Distance on the Online Word-Of-Mouth Valence of Virtual Communities. Soft Sci. 31 (04), 117-121+144. doi:10.13956/j.ss.10018409.2017.04.26

Che, C., Ma, W. Q., and Cao, S. F. (2015). Research on Time Distance, Social Distance and the Effect of Online Shopping Decision Framework. Commercial Res. 2015 (9), 130-136. doi:10.13902/j.cnki.syyj.2015.09.019

Che, C., Qi, X. L., Ma, W. Q., and Shao, D. X. (2017b). An Empirical Study on the Influencing Factors of Mobile Social Network Marketing Effectiveness. Chin. J. Manag. Sci. 25 (5), 145-149. doi:10.16381/j.cnki.issn1003-207x.2017. 05.017

Che, C., Wu, G. H., and Zhang, Z. H. (2020). Research on the Influence of Price Discount Level on Con5sumers' Purchase Intention. J. Commercial Econ. 2020 (23), 76-79. CNKI:SUN:SYJJ.0.2020-23-021.

Che, C., Zhang, X., Chen, F., Zhao, L., and Zhang, Z. (2021). A Model of Waste Price in a Symbiotic Supply Chain Based on Stackelberg Algorithm. Sustainability 13 (4), 1740. doi:10.3390/SU13041740

Che, C., Zhang, Z., Zhang, X., and Chen, Y. (2021b). Two-Stage Pricing Decision for Low-Carbon Products Based on Consumer Strategic Behaviour. Complexity 2021 (12), 1-12. doi:10.1155/2021/6633893

Chen, J.-Y., Dimitrov, S., and Pun, H. (2019). The Impact of Government Subsidy on Supply Chains' Sustainability Innovation. Omega 86 (03), 42-58. doi:10. 1016/j.omega.2018.06.012

Chen, J., Liang, L., Yao, D.-Q., and Sun, S. (2017). Price and Quality Decisions in Dual-Channel Supply Chains. Eur. J. Oper. Res. 259 (03), 935-948. doi:10.1016/ j.ejor.2016.11.016

Chen, J., Zhang, H., and Sun, Y. (2012). Implementing Coordination Contracts in a Manufacturer Stackelberg Dual-Channel Supply Chain. Omega 40 (5), 571-583. doi:10.1016/j.omega.2011.11.005

Claudia, K., and Sophie, S. (2019). Sustainable Finance: Political Challenges of Development and Implementation of Framework Conditions. Green. Finance 1 (3), 237-248. doi:10.3934/GF.2019.3.237

Deng, Y. Q. (2020). Research on green Finance Supporting the Development of green Economy in the post-epidemic Period. Beijing Financial Rev. 01, 109-116. CNKI:SUN:BJRP.0.2020-01-013.

Ding, Z. G., Xu, H. W., and Xu, Q. (2020). Decision-making of Low-Carbon Technology Adoption in Supply Chain Supported by Green Credit. Soft Sci. 34 (12), 74-80. doi:10.13956/j.ss.1001-8409.2020.12.12

\section{FUNDING}

This research was funded by the Qingdao Social Science Planning Research Project (QDSKL1901037), the Fundamental Research Funds for the Central Universities (19CX04010B), and the Shandong Soft Science Research Program General Project (2020RKE28013).

\section{ACKNOWLEDGMENTS}

We would like to thank reviewers and the editor-in-charge for valuable time on the article. And we are grateful to all the foundations that support us.

Du, S., Ma, F., Fu, Z., Zhu, L., and Zhang, J. (2015). Game-theoretic Analysis for an Emission-dependent Supply Chain in a 'cap-And-Trade' System. Ann. Oper. Res. 228 (1), 135-149. doi:10.1007/s10479-011-0964-6

He, Y., Chen, Z. H., and Liao, N. (2020). The Impact Mechanism of Government Subsidy Approach on Manufacturer's Decision-Making in green Supply Chain. Chin. J. Manag. Sci., 1-12. doi:10.16381/j.cnki.issn1003-207x.2019.1854

Huang, R. F., Sun, J. F., and Wang, J. (2020). Supply Chain Optimization Subject to Capital Constraints under Carbon Quota and Trading Mechanism. Operations Res. Manag. Sci. 29 (06), 82-89. CNKI:SUN:YCGL.0.2020-06-011.

Huo, Y. F., Deng, Q., and Yang, L. X. (2014). Research on Joint Financing of Small and Medium-Sized Enterprises under Capital Constraint. Ind. Eng. Manag. 19 (05), 24-30. doi:10.19495/j.cnki.1007-5429.2014.05.005

Julien, C., Stéphane, G., Khaled, G., and Ji, Q. (2021). Green Finance and the Restructuring of the Oil-Gas-Coal Business Model under Carbon Asset Stranding Constraints. Energy Policy 149, 112055. doi:10.1016/j.enpol.2020. 112055

Kevin, C., Dilip, C., and JamesHess, D. (2003). Direct Marketing, Indirect Profits: A Strategic Analysis of Dual-Channel Supply-Chain Design. Manag. Sci. 49 (1). doi: $10.1287 / \mathrm{mnsc}$.49.1.1.12749

Li, M., Zhang, X., and Dan, B. (2021). Cooperative Advertising Contract Design in a Supply Chain with an Offline Showroom under Asymmetric Information. J. Oper. Res. Soc. (5), 1-12. doi:10.1080/01605682.2020.1843974

Li, T., Zhang, R., Zhao, S., and Liu, B. (2019). Low Carbon Strategy Analysis under Revenue-Sharing and Cost-Sharing Contracts. J. Clean. Prod. 212, 1462-1477. doi:10.1016/j.jclepro.2018.11.282

Li, Y. Y. (2020). Research on the Development of green Bonds under the Impact of the New crown Pneumonia Epidemic. Finance \& Economy (09), 65-70+77. doi:10.14057/j.cnki.cn43-1156/f.2020.09.007

Liang, X., and Wei, C. L. (2020). Study on Innovation and Coordination Strategy of Dual Channel Supply Chain under Government Double Subsidies. Ind. Eng. Manag. 25 (06), 172-182. doi:10.19495/j.cnki.1007-5429.2020.06.020

Liao, N., Lu, C., and He, Y. (2021). Research on the Strategy of Cooperative Emission Reduction in Supply Chain Involving ESCO under Carbon Trading Policy. Chin. J. Manag. Sci. 29 (02), 160-167. doi:10.16381/j.cnki.issn1003207x.2021.02.017

Ma, Q. Z., Song, H. Q., and Chen, G. Y. (2014). Research on Product Pricing and Output Decision-Making in a Supply Chain Environment Considering Carbon Trading. Chin. J. Manag. Sci. 22 (08), 37-46. doi:10.16381/j.cnki.issn1003-207x. 2014.08.001

Ma, W.-m., Zhao, Z., and Ke, H. (2013). Dual-channel Closed-Loop Supply Chain with Government Consumption-Subsidy. Eur. J. Oper. Res. 226 (2), 221-227. doi:10.1016/j.ejor.2012.10.033

Phoebe, G. S., and Takashi, K. (2020). Examining Risk and Return Profiles of Renewable Energy Investment in Developing Countries: the Case of the Philippines. Green. Finance 2 (2), 135-150. doi:10.3934/GF.2020008

Qin, J., Zhao, Y., and Xia, L. (2018). Carbon Emission Reduction with Capital Constraint under Greening Financing and Cost Sharing Contract. Ijerph 15 (4), 750. doi:10.3390/ijerph15040750 
Subramanian, R., Gupta, S., and Talbot, B. (2007). Compliance Strategies under Permits for Emissions. Prod. Operations Manag. 16 (6). doi:10.1111/j.19375956.2007.tb00294.x

Sun, Z. L., Wang, X. P., Zhan, H. X., and Ruan, J. H. (2020). Game Analysis in a Manufacturer Dual-Channel Supply Chain with Different Power Structures. Chin. J. Manag. Sci. 28 (09), 154-163. doi:10.16381/j.cnki.issn1003-207x.2018. 0501

Tan, Y. H., Cao, X. Y., and Cao, L. (2017). Supply Chain Operation Strategy and Coordination Research under the Carbon Emission Trading Mechanism. Operations Res. Manag. Sci. 26 (03), 36-42. CNKI:SUN:YCGL.0.2017-03-005.

Toyo, K. (2020). Private Governance Schemes for green Bond Standard: Influence on Public Authorities' Policy Making. Green. Finance 2 (1), 35-54. doi:10.3934/ GF.2020003

Wang, D. P., Li, X. Y., and Zhao, L. (2018). Study on the Coordination of Supply Chain Based on Carbon Emissions Trading Considering the Manufacturers' Competition. Operations Res. Manag. Sci. 27 (04), 62-71. CNKI:SUN: YCGL.0.2018-04-011.

Wang, D. P., and Wang, T. T. (2020). Dynamic Optimization of Cooperation on Carbon Emission Reduction and Low-Carbon Propaganda in Supply Chain under Premium and Penalty of Government. Operations Res. Manag. Sci. 29 (04), 113-120. doi:10.12005/orms.2020.0097

Wang, W. L., Wang, F. L., and Zhang, S. X. (2020). Research on Coordination Contract of Dual-Channel Supply Chain Considering Low-Carbon Efforts. Manag. Rev. 33 (4), 315-326. doi:10.14120/j.cnki.cn11-5057/f.20200914.003

Wang, Y., and Zhi, Q. (2016). The Role of Green Finance in Environmental Protection: Two Aspects of Market Mechanism and Policies : Two Aspects of Market Mechanism and Policies[J]. Energ. Proced. 104 (104), 311-316. doi:10. 1016/j.egypro.2016.12.053

Xu, X. F., Lin, Z. R., and Zhu, J. (2020b). DVRP with Limited Supply and Variable Neighborhood Region in Refined Oil Distribution. Ann. Operations Res. 2020. doi:10.1007/s10479-020-03780-9

Xu, X., Hao, J., Yu, L., and Deng, Y. (2019a). Fuzzy Optimal Allocation Model for Task-Resource Assignment Problem in a Collaborative Logistics Network. IEEE Trans. Fuzzy Syst. 27 (5), 1112-1125. doi:10.1109/TFUZZ.2018.2826479

$\mathrm{Xu}, \mathrm{X}$., Hao, J., and Zheng, Y. (2020a). Multi-objective Artificial Bee Colony Algorithm for Multi-Stage Resource Leveling Problem in Sharing Logistics
Network. Comput. Ind. Eng. 142 (4), 106338. doi:10.1016/j.cie.2020. 106338

Xu, X., Wei, Z., Ji, Q., Wang, C., and Gao, G. (2019b). Global Renewable Energy Development: Influencing Factors, Trend Predictions and Countermeasures. Resour. Pol. 63 (10), 101470. doi:10.1016/j.resourpol.2019.101470

Yang, L., Zhang, Q., and Zhang, Z. Y. (2017). Channel Selection and Carbon Emissions Reduction Policies in Supply Chains with the Cap-And-Trade Scheme. J. Manag. Sci. China 20 (11), 75-87. CNKI:SUN:JCYJ.0.2017-11-007.

Zhang, D., Zhang, Z., Ji, Q., Lucey, B., and Liu, J. (2021). Board Characteristics, External Governance and the Use of Renewable Energy: International Evidence. J. Int. Financial Markets, Institutions Money 72, 101317. doi:10.1016/j.intfin. 2021.101317

Zhou, B. G. (2019). Research on the Structure Design and Selection Strategy of Dual-Channel Supply Chain. Manag. Rev. 06, 247-257. doi:10.14120/j.cnki. cn11-5057/f.2019.06.007

Zhou, Y. S., He, J., and Cui, J. L. (2020). The Construction of green Supply Chain for New Retail Enterprises Based on green Financial Loans. J. Commercial Econ. 09, 165-168. CNKI:SUN:SYJJ.0.2020-09-044.

Zhou, Y. S., Liang, S. H., Liu, S. Q., and Wang, J. (2017). The Game Study of Establishing green Supply Chain from the Perspective of green Credit. J. Manag. Sci. China 12, 87-98. CNKI:SUN:JCYJ.0.2017-12-007.

Conflict of Interest: Guo was employed the company Livestock Improvement Cooperation.

The remaining authors declare that the research was conducted in the absence of any commercial or financial relationships that could be construed as a potential conflict of interest.

Copyright (c) 2021 Che, Chen, Zhang, Zhao, Guo and Ye. This is an open-access article distributed under the terms of the Creative Commons Attribution License (CC $B Y)$. The use, distribution or reproduction in other forums is permitted, provided the original author(s) and the copyright owner(s) are credited and that the original publication in this journal is cited, in accordance with accepted academic practice. No use, distribution or reproduction is permitted which does not comply with these terms. 